\title{
Elevated depressive symptoms in metabolic syndrome in a general population of Japanese men: a cross-sectional study
}

Atsuko Sekita ${ }^{1,2}$, Hisatomi Arima ${ }^{1 *}$, Toshiharu Ninomiya ${ }^{3}$, Tomoyuki Ohara $^{1,2}$, Yasufumi Doi $^{3}$, Yoichiro Hirakawa $^{1}$, Masayo Fukuhara', Jun Hata', Koji Yonemoto ${ }^{4}$, Yukiko Ga ${ }^{1,2}$, Takanari Kitazono ${ }^{3}$, Shigenobu Kanba ${ }^{2}$ and Yutaka Kiyohara'

\begin{abstract}
Background: Uncertainty still surrounds the association between metabolic syndrome (MetS) and depression. We aimed to evaluate the association between MetS and elevated depressive symptoms in a general Japanese population.

Methods: This is a cross-sectional survey of 3,113 community-dwelling individuals aged 40 years or over. MetS was defined according to the joint interim statement. MetS was diagnosed when a subject had three or more of the following components: 1) central obesity (waist circumference $\geq 90 \mathrm{~cm}$ for men, $\geq 80 \mathrm{~cm}$ in for women); 2) elevated blood pressure ( $\geq 130 / 85 \mathrm{mmHg}$ or current use of antihypertensive medication); 3 ) hypertriglyceridemia ( $\geq 1.7 \mathrm{mmol} / \mathrm{L}$ ); 4) low HDL cholesterol (<1.0 mmol/L for men, $<1.3 \mathrm{mmol} / \mathrm{L}$ for women); and 5) elevated fasting plasma glucose ( $\geq 5.55 \mathrm{mmol} / \mathrm{L}$ or current use of antidiabetic medication). Depressive symptoms were assessed using the Center for Epidemiologic Studies Depression Scale (CES-D). The age- and multivariable-adjusted odds ratio (OR) and 95\% confidence interval (Cl) were estimated using a logistic regression model.
\end{abstract}

Results: Elevated depressive symptoms were observed in $4.3 \%$ of male and $6.3 \%$ of female participants. In men, the age-adjusted prevalence of elevated depressive symptoms was significantly higher in subjects with MetS than in those without $(7.1 \%$ versus $3.6 \%, p=0.04)$. The prevalence of elevated depressive symptoms rose progressively as the number of MetS components increased (3.5\%,3.6\%,5.8\%, and 9.2\% in male subjects with $0-1,2,3$, and $\geq 4$ components, respectively; $p=0.02$ for trend). This association remained significant even after adjustment for age, marital status, history of cardiovascular disease, smoking habit, alcohol intake, and regular exercise. In women, on the other hand, there was no clear association between MetS and depressive symptoms.

Conclusions: MetS was associated with elevated depressive symptoms in a general population of Japanese men.

Keywords: Depressive symptoms, Metabolic syndrome, Population-based, Japanese

\section{Background}

Depression is an important cause of long-term disability and dependency and is responsible for $11.8 \%$ of yearslived-with-disability [1,2]. Effective prevention of the burdens associated with depression will require a strategy based on better knowledge of its risk factors.

\footnotetext{
* Correspondence: harima@envmed.med.kyushu-u.ac.jp

'Department of Environmental Medicine, Graduate School of Medical Sciences, Kyushu University, 3-1-1 Maidashi, Higashi-ku, Fukuoka 812-8582, Japan

Full list of author information is available at the end of the article
}

Recently, a systematic review of observational studies demonstrated a link between metabolic syndrome (MetS) and depressive symptoms [3]. However, current knowledge of the association between MetS and depressive symptoms was derived mainly from studies conducted in Western populations; so it is unclear to what extent these findings apply to Asian populations. The present cross-sectional study evaluates the association of MetS with depressive symptoms in a general population of Japanese.

\section{Biomed Central}

(c) 2013 Sekita et al.; licensee BioMed Central Ltd. This is an Open Access article distributed under the terms of the Creative Commons Attribution License (http://creativecommons.org/licenses/by/2.0), which permits unrestricted use, distribution, and reproduction in any medium, provided the original work is properly cited. 


\section{Methods}

\section{Study population and design}

The Hisayama Study is a prospective cohort study of cerebro-cardiovascular diseases in a suburban community, the town of Hisayama, adjacent to of the city of Fukuoka, Japan [4-6]. Based on data from the national census, the age and occupational distributions in Hisayama have been almost identical to those in Japan as a whole since the 1960s [4]. As a part of this study, all 4330 residents of the town of Hisayama aged 40 years or older were invited to participate in a cross-sectional examination in 2007 and 2008. Among them, 3,376 residents consented to participate (participation rate $78.0 \%$ ). After the exclusion of 263 subjects with missing data on depression or MetS, a total of 3,113 subjects were included in the present analysis.

\section{Metabolic syndrome}

Information on current use of antihypertensive and antidiabetic medications was collected using a self-administered questionnaire and confirmed using the consumer drug information by trained staff. Blood pressure was measured three times after the subject had rested for at least 5 minutes prior to each measurement using a semiautomatic device (BP-203 RVIIIB; Omron Healthcare) based on the cuff-oscillometric principle with the subject in the sitting position. The mean of the three measurements was used for the analysis. Waist circumference was measured at the umbilical level in a standing position by a trained staff member. Blood samples were collected from an antecubital vein after an overnight fast for the determination of serum lipids and plasma glucose levels. Serum total cholesterol, triglyceride, and high-density lipoprotein (HDL) cholesterol concentrations were determined enzymatically. Fasting blood glucose levels were measured by the glucose oxidase method. MetS was defined based on the joint interim statement of the International Diabetes Federation Task Force on Epidemiology and Prevention; National Heart, Lung, and Blood Institute; American Heart Association; World Heart Federation; International Atherosclerosis Society; and International Association for the Study of Obesity [7]. MetS was diagnosed when a subject had three or more of the following components: 1) central obesity (waist circumference $\geq 90 \mathrm{~cm}$ for men, $\geq 80 \mathrm{~cm}$ for women); 2) elevated blood pressure $(\geq 130$ / $85 \mathrm{mmHg}$ or current use of antihypertensive medication); 3) hypertriglyceridemia ( $\geq 1.7 \mathrm{mmol} / \mathrm{L})$; 4) low HDL cholesterol ( $<1.0 \mathrm{mmol} / \mathrm{L}$ for men, $<1.3 \mathrm{mmol} / \mathrm{L}$ for women); and 5) elevated fasting plasma glucose $(\geq 5.55 \mathrm{mmol} / \mathrm{L}$ or current use of antidiabetic medication).

\section{Other covariates}

Each participant completed a self-administered questionnaire covering marital status, medical history, smoking habit, alcohol intake, and exercise. The questionnaire was checked by trained interviewers. Marital status was classified as either having a spouse on a family register or not (e.g. single, divorced). A history of cardiovascular disease was defined as prior stroke (ICD10 codes I60, I61, I63 and I64) or coronary heart disease (I20 - I25) with or without coronary revascularization (coronary intervention or bypass surgery). A smoking habit was defined as current habitual smoking of 1 or more cigarettes per day. Alcohol intake was defined as current habitual drinking of at least once per month. Subjects who engaged in sports or other forms of exercise $\geq 3$ times a week during their leisure time made up a regular exercise group.

\section{Elevated depressive symptoms}

Depressive symptoms were assessed using the Japanese, 20-item version of the Center for Epidemiologic Studies Depression Scale (CES-D) [8,9], the reliability of which has been validated [10]. Elevated depressive symptoms were defined as a CES-D score of $\geq 16$ or current use of antidepressant medication defined based on the selfadministered questionnaire and the consumer drug information.

\section{Statistical analyses}

In the present analysis, the key risk factor was MetS and its components, and the outcome was elevated depressive symptoms. All analyses were conducted separately for men and women. The prevalence of elevated depressive symptoms in each subgroup defined by MetS or its components was standardized for age distribution of the total study subjects by the direct method using 10-year age groupings. The association between components of Mets and elevated depressive symptoms was evaluated using an age-adjusted logistic regression model. The association of Mets and the number of its components with elevated depressive symptoms was evaluated using age- and multivariable-adjusted logistic regression models. The multivariable-adjusted models included age, marital status, history of cardiovascular disease, smoking habit, alcohol intake, and regular exercise as covariates. The differences in the association of MetS and the number of its components with elevated depressive symptoms between men and women were evaluated by adding interaction term(s) to the logistic regression models. $\mathrm{P}<0.05$ was considered statistically significant in all analyses. The SAS software package, version 9.2 (SAS Institute) was used for statistical analysis.

\section{Ethical considerations}

The study protocol was approved by Kyushu University Institutional Review Board for Clinical Research, and the procedures followed were in accordance with national 
guidelines. All participants provided written informed consent.

\section{Results}

The baseline characteristics of subjects with and without MetS are shown by sex in Table 1 . Subjects with MetS had higher values for waist circumference, systolic and diastolic blood pressures, serum total cholesterol, triglycerides and fasting plasma glucose; they also had lower levels of HDL cholesterol in both men and women. The frequencies of antihypertensive and antidiabetic medications were also higher in MetS subjects of both sexes. Women with MetS were older and less likely to be alcohol drinkers.

Elevated depressive symptoms were observed in 58 (4.3\%) men and 111 (6.3\%) women. Table 2 shows the age-adjusted prevalence and odds ratio [OR] for elevated depressive symptoms according to the presence of MetS components in men and women. The age-adjusted prevalence of elevated depressive symptoms was higher in men with low HDL cholesterol (age-adjusted OR 2.55 [95\% CI 1.11-5.86]) and men with elevated fasting plasma glucose (1.90 [95\% CI 1.06-3.42]). These associations remained significant even after controlling for age, marital status, history of cardiovascular disease, smoking habit, alcohol intake, and regular exercise (low HDL cholesterol: multivariable-adjusted OR $2.44 \quad$ [95\% CI 1.04-5.69], elevated fasting plasma glucose: 1.93 [95\% CI 1.07-3.49]). In women, on the other hand, there were no clear associations between MetS components and depressive symptoms (all $\mathrm{p}>0.05$ ).

Table 3 shows the association of MetS with depressive symptoms in men and women. The age-adjusted prevalence of elevated depressive symptoms was significantly higher in men with MetS than in those without it (7.1\% versus 3.6\%; age-adjusted OR 1.78 [95\% CI 1.03-3.08]). This association remained significant even after controlling for age, marital status, history of cardiovascular disease, smoking habit, alcohol intake, and regular exercise (multivariable-adjusted OR 1.82 [95\% CI 1.05-3.15]). In women, on the other hand, there were no significant associations between MetS and depressive symptoms $(\mathrm{p}=0.10 ; \mathrm{p}=0.006$ for homogeneity between men and women).

The age-adjusted prevalence and adjusted OR for elevated depressive symptoms according to the number of MetS components are shown by sex in Table 4. In men, the age-adjusted prevalence rose with the number of MetS components: it was 3.5\%, 3.6\%, 5.8\%, and 9.2\% for subjects with $0-1,2,3$, and $\geq 4$ components, respectively ( $\mathrm{p}=0.02$ for trend). A significant association was observed even after controlling for the aforementioned confounding factors $(\mathrm{p}=0.01$ for trend). When the number of MetS was used as a continuous variable, an increase in 1 component was associated with a 35\% (95\% CI 8-67\%) increase in elevated depressive symptoms. In contrast to men, women showed no clear associations between the number of MetS components and

Table 1 Characteristics of men and women with and without metabolic syndrome

\begin{tabular}{|c|c|c|c|c|c|c|}
\hline & \multicolumn{3}{|c|}{ Men } & \multicolumn{3}{|c|}{ Women } \\
\hline & $\begin{array}{l}\text { MetS (-) } \\
(n=965)\end{array}$ & $\begin{array}{l}\text { MetS (+) } \\
(\mathrm{n}=388)\end{array}$ & $P$ value & $\begin{array}{l}\text { MetS }(-) \\
(n=1261)\end{array}$ & $\begin{array}{l}\text { MetS }(+) \\
(n=499)\end{array}$ & $P$ value \\
\hline Age (years) & $63 \pm 12$ & $62 \pm 10$ & 0.14 & $62 \pm 13$ & $67 \pm 11$ & $<0.0001$ \\
\hline Single or divorced (\%) & 11.7 & 11.6 & 0.95 & 27.5 & 31.9 & 0.07 \\
\hline History of cardiovascular disease (\%) & 8.4 & 10.6 & 0.21 & 2.6 & 4.8 & 0.02 \\
\hline Antihypertensive medication (\%) & 28.2 & 44.6 & $<0.0001$ & 23.2 & 50.1 & $<0.0001$ \\
\hline Antidiabetic medication (\%) & 7.2 & 17.0 & $<0.0001$ & 1.8 & 17.6 & $<0.0001$ \\
\hline Waist circumference (cm) & $83.5 \pm 7.2$ & $92.6 \pm 6.8$ & $<0.0001$ & $81.3 \pm 9.3$ & $91.4 \pm 9.3$ & $<0.0001$ \\
\hline Systolic blood pressure (mmHg) & $129 \pm 17$ & $144 \pm 15$ & $<0.0001$ & $125 \pm 18$ & $144 \pm 16$ & $<0.0001$ \\
\hline Diastolic blood pressure (mmHg) & $79 \pm 9$ & $88 \pm 9$ & $<0.0001$ & $75 \pm 10$ & $84 \pm 10$ & $<0.0001$ \\
\hline Total cholesterol (mmol/L) & $5.10 \pm 0.87$ & $5.34 \pm 0.93$ & 0.0001 & $5.57 \pm 0.89$ & $5.73 \pm 0.93$ & 0.0008 \\
\hline Triglycerides (mmol/L) & $1.10(0.82-1.47)$ & $2.02(1.47-2.84)$ & $<0.0001$ & $0.93(0.69-1.23)$ & $1.57(1.09-2.04)$ & $<0.0001$ \\
\hline HDL cholesterol (mmol/L) & $1.65 \pm 0.42$ & $1.39 \pm 0.37$ & $<0.0001$ & $1.95 \pm 0.43$ & $1.61 \pm 0.42$ & $<0.0001$ \\
\hline Fasting plasma glucose (mmol/L) & $5.8 \pm 1.2$ & $6.7 \pm 1.6$ & $<0.0001$ & $5.3 \pm 0.7$ & $6.4 \pm 1.5$ & $<0.0001$ \\
\hline Smoking habit (\%) & 33.6 & 38.0 & 0.12 & 7.6 & 7.3 & 0.82 \\
\hline Alcohol intake (\%) & 68.0 & 71.4 & 0.22 & 33.7 & 26.7 & 0.004 \\
\hline Regular exercise (\%) & 13.7 & 12.9 & 0.70 & 10.1 & 12.6 & 0.12 \\
\hline
\end{tabular}

MetS metabolic syndrome; HDL high-density lipoprotein.

Values are mean $\pm S D$, median (interquartile range) or frequency.

The differences between subjects with and without MetS were tested by Wilcoxon tests for continuous variables and chi-square tests for categorical variables. 
Table 2 Components of metabolic syndrome and elevated depressive symptoms in men and women

\begin{tabular}{|c|c|c|c|c|}
\hline & $\begin{array}{l}\mathrm{N} \text { of cases/ } \\
\text { participants }\end{array}$ & $\begin{array}{l}\text { Age-adjusted } \\
\text { prevalence (\%) }\end{array}$ & $\begin{array}{c}\text { Age-adjusted } \\
\text { OR }(95 \% \mathrm{Cl})\end{array}$ & $P$ value \\
\hline \multicolumn{5}{|l|}{ Men } \\
\hline \multicolumn{5}{|c|}{ Central obesity } \\
\hline No & $34 / 912$ & 3.6 & Reference & \\
\hline Yes & $24 / 441$ & 5.9 & $1.61(0.94-2.77)$ & 0.08 \\
\hline \multicolumn{5}{|c|}{ Elevated BP } \\
\hline No & $21 / 582$ & 3.9 & Reference & \\
\hline Yes & $37 / 771$ & 4.9 & $1.26(0.73-2.18)$ & 0.41 \\
\hline \multicolumn{5}{|c|}{ Hypertriglyceridemia } \\
\hline No & $40 / 939$ & 4.1 & Reference & \\
\hline Yes & $18 / 414$ & 4.8 & $1.17(0.66-2.09)$ & 0.60 \\
\hline \multicolumn{5}{|c|}{ Low HDL cholesterol } \\
\hline No & $51 / 1276$ & 4.0 & Reference & \\
\hline Yes & $7 / 77$ & 8.3 & $2.55(1.11-5.86)$ & 0.03 \\
\hline \multicolumn{5}{|c|}{ Elevated FPG } \\
\hline No & $16 / 570$ & 2.9 & Reference & \\
\hline Yes & $42 / 783$ & 5.5 & $1.90(1.06-3.42)$ & 0.03 \\
\hline \multicolumn{5}{|l|}{ Women } \\
\hline \multicolumn{5}{|c|}{ Central obesity } \\
\hline No & $43 / 593$ & 7.4 & Reference & \\
\hline Yes & $68 / 1167$ & 5.9 & $0.78(0.53-1.16)$ & 0.22 \\
\hline \multicolumn{5}{|c|}{ Elevated BP } \\
\hline No & $58 / 899$ & 6.8 & Reference & \\
\hline Yes & $53 / 861$ & 6.2 & $0.91(0.61-1.36)$ & 0.65 \\
\hline \multicolumn{5}{|c|}{ Hypertriglyceridemia } \\
\hline No & $100 / 1471$ & 6.8 & Reference & \\
\hline Yes & $11 / 289$ & 3.6 & $0.54(0.28-1.01)$ & 0.05 \\
\hline \multicolumn{5}{|c|}{ Low HDL cholesterol } \\
\hline No & $102 / 1607$ & 6.3 & Reference & \\
\hline Yes & $9 / 153$ & 6.4 & $0.92(0.45-1.85)$ & 0.81 \\
\hline \multicolumn{5}{|c|}{ Elevated FPG } \\
\hline No & $71 / 1103$ & 6.5 & Reference & \\
\hline Yes & $40 / 657$ & 6.3 & $0.93(0.62-1.39)$ & 0.71 \\
\hline
\end{tabular}

$O R$ odds ratio, $95 \% \mathrm{Cl} 95 \%$ confidence interval, $B P$ blood pressure, HDL highdensity lipoprotein, $F P G$ fasting plasma glucose.

$\mathrm{OR}$ and $\mathrm{P}$ values were estimated using logistic regression models.

depressive symptoms ( $\mathrm{p}=0.17$ for trend; OR 0.9 (95\% CI 0.76-1.06) per 1 component increase; $\mathrm{p}=0.04$ for homogeneity between men and women).

\section{Discussion}

The present cross-sectional examination of a general population of Japanese demonstrated a higher prevalence of elevated depressive symptoms in male subjects with MetS compared to those without it. This association remained significant even after controlling for the effects of age, marital status, history of cardiovascular disease, smoking habit, alcohol intake, and regular exercise. Furthermore, the prevalence of elevated depressive symptoms rose with the number of MetS components. In female subjects, on the other hand, there was no clear association between MetS and depressive symptoms.

Although a number of observational studies have investigated the association between MetS and depressive symptoms, their conclusions have been inconsistent [11-29]. With regard to cross-sectional studies, a French study demonstrated elevated depressive symptoms in men and women with MetS [14]. The PPP-Bonita Study also showed close associations of MetS and its components with depressive symptoms in Finnish men and women [29]. With respect to longitudinal design research, the Whitehall II study demonstrated that the presence of MetS was associated with 38\% increased risks of future depressive symptoms in men and women in London [16]. The Health in Men Study showed that MetS was a strong predictor of the future development of depression in elderly Australian men [17]. A positive association between MetS and the incidence of depression was also reported in an office-based study of 956 Japanese men [18]. On the other hand, a cohort study from France demonstrated no significant association between MetS and depressive symptoms in elderly subjects aged about 70-90 years old [24]. A recent systematic review and a meta analysis including all these studies, however, demonstrated a clear relationship between MetS and depression. Our findings from the Hisayama Study suggest that the concept of a link between MetS and depression is likely to be applicable to Japanese men.

Several population-based observational studies have reported the association between MetS and depression separately for men and women. A cross-sectional study in France demonstrated that depression and depressive symptoms were associated with MetS, irrespective of gender [14]. A cross-sectional study in Poland showed that MetS was observed more frequently among male subjects with depressive symptoms than those without, while there were no associations among women [12]. A cross-sectional study in the United States reported that women with a history of major depressive episode were twice as likely to have metabolic syndrome compared with those without such a history, but men with history of depression were not significantly more likely to have MetS [11]. A cohort study in Finland found that MetS was not associated with depression or anxiety in either men or women [13]. Therefore, there has been significant inconsistency in gender differences in the link between MetS and depression in Western populations. With regard to Asian populations, on the other hand, a cohort study of Japanese male employees showed a 
Table 3 Metabolic syndrome and elevated depressive symptoms in men and women

\begin{tabular}{|c|c|c|c|c|c|c|}
\hline & \multirow[t]{2}{*}{$\mathrm{N}$ of cases/participants } & \multicolumn{3}{|c|}{ Age-adjusted } & \multicolumn{2}{|c|}{ Multivariable-adjusted $^{*}$} \\
\hline & & Prevalence (\%) & OR (95\% Cl) & $P$ value & OR $(95 \% \mathrm{Cl})$ & $P$ value \\
\hline \multicolumn{7}{|l|}{ Men } \\
\hline MetS (-) & $35 / 965$ & 3.6 & Reference & & Reference & \\
\hline MetS (+) & $23 / 388$ & 7.1 & $1.78(1.03-3.08)$ & 0.04 & $1.82(1.05-3.15)$ & 0.03 \\
\hline \multicolumn{7}{|l|}{ Women } \\
\hline MetS (-) & $87 / 1261$ & 7.0 & Reference & & Reference & \\
\hline MetS $(+)$ & $24 / 499$ & 5.2 & $0.66(0.41-1.06)$ & 0.08 & $0.67(0.42-1.08)$ & 0.10 \\
\hline
\end{tabular}

MetS metabolic syndrome, OR odds ratio, 95\% Cl 95\% confidence interval.

$\mathrm{OR}$ and $\mathrm{P}$ values were estimated using logistic regression models.

"Adjusted for age, marital status, history of cardiovascular disease, smoking habit, alcohol intake and regular exercise.

positive relationship between MetS and depression [18]. A cross-sectional study of Japanese subjects in Takarazuka City demonstrated that the mean depression score was higher for men with MetS than those without it, while depression was not associated with MetS in women [25]. In the present study of Japanese subjects, MetS was associated with elevated depressive symptoms in men but not in women. In Asian populations, MetS may be associated with depressive symptoms only in men.

One of the mechanisms underlying the association between MetS and depressive symptoms is thought to be the stress-induced hyperactivity of the hypothalamicpituitary-adrenal (HPA) axis, which is common in depression [30-32] and could lead to metabolic alterations [33-35]. Chronic stress has also been shown to increase the risk of metabolic disorders through elevated sympathetic activity [36]. Another potential mechanism is that cerebral small vessel disease associated with MetS [37] can increase the risk of late-life depression [38,39]. It is also possible that behavioral factors associated with depressive symptoms, such as physical inactivity and poor diet, contribute to central adiposity and metabolic disorders.

Another important finding from the present analysis is the lack of associations between MetS and depressive symptoms in women. This finding is consistent with a previous cross-sectional study. The SOPKARD project demonstrated clear associations between MetS and depressive symptoms in Polish men but not in Polish women [12]. The reason for this discrepancy has not been clearly resolved, but it may be attributable to heterogeneity in genetic factors, hormonal factors, socioeconomic factors and social roles between men and women.

There were several limitations to this study. Because of the cross-sectional nature of the study, we were unable to determine whether or not there was a causal association between MetS and the development of depressive symptoms. In addition, we were unable to address the potential mechanisms underlying the reported associations, the self-reported covariates had somewhat limited accuracy, and the study lacked definite diagnosis

Table 4 The number of metabolic syndrome components and elevated depressive symptoms in men and women

\begin{tabular}{|c|c|c|c|c|c|c|}
\hline \multirow[b]{2}{*}{ Number of MetS components } & \multirow[t]{2}{*}{$\mathrm{N}$ of cases/participants } & \multicolumn{3}{|c|}{ Age-adjusted } & \multicolumn{2}{|c|}{ Multivariable-adjusted* } \\
\hline & & Prevalence (\%) & OR $(95 \% \mathrm{Cl})$ & $P$ trend & OR $(95 \% \mathrm{Cl})$ & $P$ trend \\
\hline \multicolumn{7}{|l|}{ Men } \\
\hline $0-1$ & $20 / 567$ & 3.5 & Reference & & Reference & \\
\hline 2 & $15 / 398$ & 3.6 & $0.80(0.44-1.45)$ & & $0.84(0.46-1.55)$ & \\
\hline 3 & $12 / 250$ & 5.8 & $1.17(0.61-2.25)$ & & $1.20(0.62-2.31)$ & \\
\hline$\geq 4$ & $11 / 138$ & 9.2 & $2.43(1.22-4.86)$ & 0.02 & $2.47(1.22-4.96)$ & 0.01 \\
\hline \multicolumn{7}{|l|}{ Women } \\
\hline $0-1$ & $56 / 782$ & 7.4 & Reference & & Reference & \\
\hline 2 & $31 / 479$ & 6.3 & $1.03(0.67-1.58)$ & & $1.05(0.68-1.62)$ & \\
\hline 3 & $15 / 360$ & 4.4 & $0.58(0.33-1.01)$ & & $0.56(0.32-0.99)$ & \\
\hline$\geq 4$ & $9 / 139$ & 7.5 & $1.01(0.50-2.06)$ & 0.12 & $1.10(0.54-2.25)$ & 0.17 \\
\hline
\end{tabular}

MetS metabolic syndrome, OR odds ratio, 95\% CI 95\% confidence interval.

$O R$ and $P$ values were estimated using logistic regression models.

*Adjusted for age, marital status, history of cardiovascular disease, smoking habit, alcohol intake and regular exercise. 
of depression based on structured interviews with psychiatrists using standard criteria.

\section{Conclusions}

In conclusion, MetS was associated with elevated depressive symptoms in a general population of Japanese men. Screening of depressive symptoms in men with MetS is likely to aid in the early detection and treatment of depression, and might be able to provide additional protection against the enormous burden of mental disorders in Japan.

\section{Abbreviations}

MetS: Metabolic syndrome; CES-D: Center for epidemiologic studies depression scale; HDL: High-density lipoprotein; OR: Odds ratio; $\mathrm{Cl}$ : Confidence interval; HPA: Hypothalamic-pituitary-adrenal.

\section{Competing interests}

The authors declare that they have no competing interests.

\section{Authors' contributions}

AS conducted the statistical analyses, wrote the manuscript, and reviewed and edited the manuscript. AS is the guarantor of this work, had full access to all data in the study and takes responsibility for the integrity of the data and the accuracy of the data analysis. HA contributed to discussion and reviewed and edited the manuscript. TN, TO and YD contributed to discussion. YH brushed up the accuracy of data. MF, JH, KY, YG, TK and SK contributed to discussion. YK is responsible for overall management of the Hisayama Study, and reviewed and edited the manuscript. All authors read and approved the final manuscript.

\section{Acknowledgements}

This study was funded in part by Grants-in-Aid for Scientific Research on Innovative Areas (22116010) and for Scientific Research (A) (22240073) and (C) $(22590892,23590797,23590798,23500842,24590797$, and 24590796) from the Ministry of Education, Culture, Sports, Science and Technology of Japan and by Health and Labour Sciences Research Grants of the Ministry of Health, Labor and Welfare of Japan (Comprehensive Research on Aging and Health: H20-Chouju-004; Comprehensive Research on Life-Style Related Diseases including Cardiovascular Diseases and Diabetes Mellitus: H22Junkankitou [Seishuu]-Ippan-005, H22-Junkankitou [Seishuu]-Ippan-017, H23Junkankitou [Seishuu]-Ippan-002, and H23-Junkankitou [Seishuu]-Ippan-005; and Comprehensive Research on Dementia: H23-Ninchisho-Ippan-004).

\section{Author details}

'Department of Environmental Medicine, Graduate School of Medical Sciences, Kyushu University, 3-1-1 Maidashi, Higashi-ku, Fukuoka 812-8582, Japan. ${ }^{2}$ Department of Neuropsychiatry, Graduate School of Medical Sciences, Kyushu University, 3-1-1 Maidashi, Higashi-ku, Fukuoka 812-8582, Japan. ${ }^{3}$ Department of Medicine and Clinical Science, Graduate School of Medical Sciences, Kyushu University, 3-1-1 Maidashi, Higashi-ku, Fukuoka 812-8582, Japan. ${ }^{4}$ Biostatistics Center, Kurume University, 67 Asahimachi، Kurume 830-0011, Japan

Received: 13 February 2013 Accepted: 5 September 2013 Published: 18 September 2013

\section{References}

1. Murray CJL, Lopez AP: Global burden of disease: a comprehensive assessment of mortality and disability from diseases, injuries, and risk factors in 1990 and projected to 2020. Cambridge: Harvard University Press; 1996.

2. Prince M, Patel V, Saxena S, Maj M, Maselko J, Phillips MR, Rahman A: No health without mental health. Lancet 2007, 370:859-877.

3. Pan A, Keum N, Okereke OI, Sun Q, Kivimaki M, Rubin RR, Hu FB. Bidirectional association between depression and metabolic syndrome: a systematic review and meta-analysis of epidemiological studies. Diabetes Care 2012, 35:1171-1180
4. Ohmura T, Ueda K, Kiyohara Y, Kato I, Iwamoto H, Nakayama K, Nomiyama K, Ohmori S, Yoshitake T, Shinkawu A, et al: Prevalence of type 2 (non-insulin-dependent) diabetes mellitus and impaired glucose tolerance in the Japanese general population: the Hisayama study. Diabetologia 1993, 36:1198-1203.

5. Arima H, Kubo M, Yonemoto K, Doi Y, Ninomiya T, Tanizaki Y, Hata J, Matsumura K, lida M, Kiyohara Y: High-sensitivity C-reactive protein and coronary heart disease in a general population of Japanese: the Hisayama study. Arterioscler Thromb Vasc Biol 2008, 28:1385-1391.

6. Sekita A, Ninomiya T, Tanizaki Y, Doi Y, Hata J, Yonemoto K, Arima H, Sasaki K, lida M, Iwaki T, et al: Trends in prevalence of Alzheimer's disease and vascular dementia in a Japanese community: the Hisayama study. Acta Psychiatr Scand 2010, 122:319-325.

7. Alberti KG, Eckel RH, Grundy SM, Zimmet PZ, Cleeman Jl, Donato KA, Fruchart JC, James WP, Loria CM, Smith SC Jr: Harmonizing the metabolic syndrome: a joint interim statement of the international diabetes federation task force on epidemiology and prevention; national heart, lung, and blood institute; american heart association; world heart federation; international atherosclerosis society; and international association for the study of obesity. Circulation 2009, 120:1640-1645.

8. Radloff LS: The CES-D scale: a self-report depression scale for research in the general population. Applied Psychol Measure 1977, 1:385-401.

9. Roberts RE, Vernon SW: The center for epidemiologic studies depression scale: its use in a community sample. Am J Psychiatry 1983, 140:41-46.

10. Sima S, Kano T, Kitamura T, Asai M: A new scale of depressive symptoms (in Japanese). Clinical Psychiatry 1985, 27:717-723.

11. Kinder LS, Carnethon MR, Palaniappan LP, King AC, Fortmann SP: Depression and the metabolic syndrome in young adults: findings from the third national health and nutrition examination survey. Psychosom Med 2004, 66:316-322.

12. Gil K, Radzillowicz P, Zdrojewski T, Pakalska-Korcala A, Chwojnicki K, Piwonski J, Ignaszewska-Wyrzykowska A, Zaluga L, Mielczarek M, Landowski J, et al: Relationship between the prevalence of depressive symptoms and metabolic syndrome. Results of the SOPKARD project. Kardiol Pol 2006, 64:464-469.

13. Herva A, Rasanen P, Miettunen J, Timonen M, Laksy K, Veijola J, Laitinen J, Ruokonen A, Joukamaa M: Co-occurrence of metabolic syndrome with depression and anxiety in young adults: the Northern Finland 1966 birth cohort study. Psychosom Med 2006, 68:213-216.

14. Skilton MR, Moulin P, Terra JL, Bonnet F: Associations between anxiety, depression, and the metabolic syndrome. Biol Psychiatry 2007 62:1251-1257.

15. Vogelzangs N, Suthers K, Ferrucci L, Simonsick EM, Ble A, Schrager M, Bandinelli S, Lauretani F, Giannelli SV, Penninx BW: Hypercortisolemic depression is associated with the metabolic syndrome in late-life. Psychoneuroendocrinol 2007, 32:151-159.

16. Akbaraly TN, Kivimaki M, Brunner EJ, Chandola T, Marmot MG, SinghManoux A, Ferrie JE: Association between metabolic syndrome and depressive symptoms in middle-aged adults: results from the Whitehall II study. Diabetes Care 2009, 32:499-504.

17. Almeida OP, Calver J, Jamrozik K, Hankey GJ, Flicker L: Obesity and metabolic syndrome increase the risk of incident depression in older men: the health in men study. Am J Geriatr Psychiatry 2009, 17:889-898.

18. Takeuchi T, Nakao M, Nomura K, Inoue M, Tsurugano S, Shinozaki Y, Yano E: Association of the metabolic syndrome with depression and anxiety in Japanese men: a 1-year cohort study. Diabetes Metab Res Rev 2009, 25:762-767.

19. Vanhala M, Jokelainen J, Keinanen-Kiukaanniemi S, Kumpusalo E, Koponen H: Depressive symptoms predispose females to metabolic syndrome: a 7-year follow-up study. Acta psychiatr Scand 2009, 119:137-142.

20. Vogelzangs N, Beekman AT, Dik MG, Bremmer MA, Comijs HC, Hoogendijk WJ, Deeg DJ, Penninx BW: Late-life depression, cortisol, and the metabolic syndrome. Am J Geriatr Psychiatry 2009, 17:716-721.

21. East C, Willis BL, Barlow CE, Grannemann BD, FitzGerald SJ, DeFina LF, Trivedi MH: Depressive symptoms and metabolic syndrome in preventive healthcare: the cooper center longitudinal study. Metab Syndr Relat Disord 2010, 8:451-457.

22. Kobrosly RW, van Wijngaarden E: Revisiting the association between metabolic syndrome and depressive symptoms. Ann Epidemiol 2010 20:852-855.

23. Lamers F, de Jonge $P$, Nolen WA, Smit JH, Zitman FG, Beekman AT, Penninx BW: Identifying depressive subtypes in a large cohort study: results from 
the Netherlands study of depression and anxiety (NESDA). J Clin Psychiatry 2010, 71:1582-1589.

24. Akbaraly TN, Ancelin ML, Jaussent I, Ritchie C, Barberger-Gateau P, Dufouil C, Kivimaki M, Berr C, Ritchie K: Metabolic syndrome and onset of depressive symptoms in the elderly: findings from the three-city study. Diabetes Care 2011, 34:904-909.

25. Nishina M, Nishina K, Ohira T, Makino K, Iso H: Associations of psychological distress with metabolic syndrome among Japanese urban residents. J Atheroscler Thromb 2011, 18:396-402.

26. Vogelzangs N, Beekman AT, Boelhouwer IG, Bandinelli S, Milaneschi Y Ferrucci L, Penninx BW: Metabolic depression: a chronic depressive subtype? Findings from the InCHIANTI study of older persons. J Clin Psychiatry 2011, 72:598-604.

27. Kahl KG, Greggersen W, Schweiger U, Cordes J, Balijepalli C, Losch C, Moebus S: Prevalence of the metabolic syndrome in unipolar major depression. Eur Arch Psychiatry Clin Neurosci 2012, 262:313-320.

28. Seppala J, Vanhala M, Kautiainen H, Eriksson J, Kampman O, Mantyselka P, Oksa H, Ovaskainen Y, Viikki M, Koponen H: Prevalence of metabolic syndrome in subjects with melancholic and non-melancholic depressive symptoms. A Finnish population-based study. J Affect Disord 2012, 136:543-549.

29. Pyykkonen AJ, Raikkonen K, Tuomi T, Eriksson JG, Groop L, Isomaa B: Association between depressive symptoms and metabolic syndrome is not explained by antidepressant medication: results from the PPP-Botnia Study. Ann Med 2012, 44:279-288.

30. Nemeroff CB, Widerlov E, Bissette G, Walleus H, Karlsson I, Eklund K, Kilts CD, Loosen PT, Vale W: Elevated concentrations of CSF corticotropin-releasing factor-like immunoreactivity in depressed patients. Science 1984, 226:1342-1344.

31. Wolkowitz OM, Reus VI, Manfredi F, Ingbar J, Brizendine L, Weingartner H: Ketoconazole administration in hypercortisolemic depression. Am J Psychiatry 1993, 150:810-812.

32. Jabben N, Nolen WA, Smit JH, Vreeburg SA, Beekman AT, Penninx BW: Co-occurring manic symptomatology influences HPA axis alterations in depression. J Psychiatr Res 2011, 45:1208-1213.

33. Rosmond R: Role of stress in the pathogenesis of the metabolic syndrome. Psychoneuroendocrinol 2005, 30:1-10.

34. Anagnostis P, Athyros VG, Tziomalos K, Karagiannis A, Mikhailidis DP: Clinical review: the pathogenetic role of cortisol in the metabolic syndrome: a hypothesis. J Clin Endocrinol Metab 2009, 94:2692-2701.

35. Tentolouris N, Argyrakopoulou G, Katsilambros N: Perturbed autonomic nervous system function in metabolic syndrome. Neuromolecular Med 2008, 10:169-178.

36. Licht CM, Vreeburg SA, van Reedt Dortland AK, Giltay EJ, Hoogendijk WJ, DeRijk RH, Vogelzangs N, Zitman FG, de Geus EJ, Penninx BW: Increased sympathetic and decreased parasympathetic activity rather than changes in hypothalamic-pituitary-adrenal axis activity is associated with metabolic abnormalities. J Clin Endocrinol Metab 2010, 95:2458-2466.

37. Bokura H, Yamaguchi S, lijima K, Nagai A, Oguro H: Metabolic syndrome is associated with silent ischemic brain lesions. Stroke 2008, 39:1607-1609.

38. Herrmann LL, Le Masurier M, Ebmeier KP: White matter hyperintensities in late life depression: a systematic review. J Neurol Neurosurg Psychiatry 2008, 79:619-624.

39. Santos M, Gold G, Kovari E, Herrmann FR, Bozikas VP, Bouras C, Giannakopoulos P: Differential impact of lacunes and microvascular lesions on poststroke depression. Stroke 2009, 40:3557-3562

\section{Submit your next manuscript to BioMed Central and take full advantage of:}

- Convenient online submission

- Thorough peer review

- No space constraints or color figure charges

- Immediate publication on acceptance

- Inclusion in PubMed, CAS, Scopus and Google Scholar

- Research which is freely available for redistribution

Submit your manuscript at www.biomedcentral.com/submit
C Biomed Central 